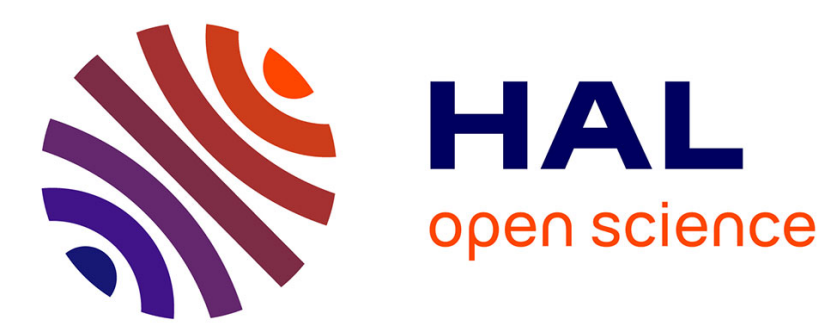

\title{
HOT ELECTRON RELIABILITY OF DEEP SUBMICRON MOS TRANSISTORS
}

G. Reimbold, F. Paviet-Salomon, H. Haddara, G. Guegan, S. Cristoloveanu

\section{To cite this version:}

G. Reimbold, F. Paviet-Salomon, H. Haddara, G. Guegan, S. Cristoloveanu. HOT ELECTRON RELIABILITY OF DEEP SUBMICRON MOS TRANSISTORS. Journal de Physique Colloques, 1988, 49 (C4), pp.C4-665-C4-668. 10.1051/jphyscol:19884139 . jpa-00227876

\section{HAL Id: jpa-00227876 https://hal.science/jpa-00227876}

Submitted on 1 Jan 1988

HAL is a multi-disciplinary open access archive for the deposit and dissemination of scientific research documents, whether they are published or not. The documents may come from teaching and research institutions in France or abroad, or from public or private research centers.
L'archive ouverte pluridisciplinaire HAL, est destinée au dépôt et à la diffusion de documents scientifiques de niveau recherche, publiés ou non, émanant des établissements d'enseignement et de recherche français ou étrangers, des laboratoires publics ou privés. 
HOT ELECTRON RELIABILITY OF DEEP SUBMICRON MOS TRANSISTORS

\author{
G. REIMBOLD, F. PAVIET-SALOMON* , H. HADDARA*, G. GUEGAN and \\ S. CRISTOLOVEANU*
}

\author{
LETI, CENG, 85X, F-38041 Grenoble Cedex, France \\ "Laboratoire de Physique des Composants à Semiconducteurs, ENSERG. \\ F-38031 Grenoble Cedex, France
}

Résumé - Nous étudions la dégradation des performances des transistors MOS ultra-courts $(0.3 \mathrm{Mm}-0.6 \mathrm{Mm})$ engendrée par l'injection de porteurs chauds. Ces dispositifs ont un canal $\mathrm{N}$, une structure conventionnelle (non LDD) et ont éte optimisés pour fonctionner à $3 \mathrm{~V}$. Plusieurs types de contraintes ont été analysés. Un suivi systématique des paramètres importants a été réalisé en cours de vieillissement, la dégradation étant ensuite évalué par des méthodes de caractérisation fine. L'influence des tensions d'alimentation sur la durée de vie des dispositifs est étudiée. Ces résultats sont interprétés en tenant compte de l'extension de la zone de défauts et du taux de génération locale d'états d'interface.

\begin{abstract}
The hot electron induced degradation of fully optimized N-channel MOSFET's, having channel lengths in the range $0.3 \mathrm{~mm}-0.6 \mathrm{~mm}$, is systematically investigated. The created defects and their influence on the device performance are evaluated with very sensitive techniques and explained using $2 \mathrm{D}$ modelling. The device lifetime is analysed as a function of the biasing conditions. These results are interpreted by taking into consideration the extension of the defective region as well as the local generation rate of interface states.
\end{abstract}

\title{
1 - INTRODUCTION
}

Hot electron reliability of MOS transistors is a key problem for the long term stability of modern VLSI circuits. During the last decade much effort has been devoted to the study of hot carrier-induced degradation in MOSFET's longer than $1 \mathrm{Mm}$. Although many important aspects have been clarified, neither a complete description of the physical mechanisms has been given nor a fully satisfactory technological solution proposed to eliminate aging problems. In addition, an accentuation of the hot carrier deterioration of the $\mathrm{Si} / \mathrm{SiO}_{2}$ interface is expected to occur as the new generation of submicron transistors emerges. Other fundamental questions are related both to the possibility of avoiding LDD structures and the impact of a bias supply limitation at 3 $\mathrm{V}$. However, a very small amount of experimental data was reported on the aging of half-micron transistors.

There are three original aspects in this work:

(1) use of fully optimized deep submicron MOSFET's with $0.3-0.6 \mu \mathrm{m}$ channel lengths,

(2) systematic aging under different stressing conditions and for very long periods of time $\left(6.10^{5}\right.$ seconds),

(3) monitoring of the evolution of the main device parameters during stress, followed by a detailed inspection of the interface damage at the end of the stress using very sensitive characterization techniques (dynamic transconductance and charge pumping) as well as an accurate parameter extraction method .

\section{2 - EXPERIMENTAL CONDITIONS}

The transistors used in this study have been fabicated with electron beam lithography. They have channel widths of $20 \mathrm{~mm}, 15 \mathrm{~nm}$ gate oxides, $0.17 \mathrm{~mm}$ junction depth and nominal gate lengths from 0.4 to $0.8 \mathrm{\mu m}$ ( the effective channel length being about $0.1 \mathrm{\mu m}$ shorter). They were optimized for a $3 \mathrm{~V}$ bias supply in order to avoid the use of LDD structures $/ 1 /$. Stress was performed at different gate and drain voltages. The aging effects of low $(1.4 \mathrm{~V})$ and higher $(3.3 \mathrm{~V})$ gate biases were compared by keeping the drain voltage in the saturation region before the avalanche onset.

\begin{tabular}{|c|c|c|c|c|c|}
\hline Parameter & $\begin{array}{c}\Delta \mathrm{V}_{\mathrm{T}} \\
(\mathrm{V})\end{array}$ & $\frac{\Delta \mathrm{Gm}}{\mathrm{Gm}}$ & $\frac{\Delta \mathrm{Isat}}{\text { Isat }}$ & $\frac{\Delta \mathrm{Ilin}}{\mathrm{Ilin}}$ & $(\mathrm{\Delta S} / \mathrm{dc})$ \\
\hline $\mathrm{n}$ & 0.64 & 0.42 & 0.42 & 0.46 & 0.71 \\
\hline $\mathrm{A}$ & $10^{-4}$ & $2.10^{-3}$ & $1.310^{-3}$ & $7.10^{-4}$ & $3.10^{-6}$ \\
\hline
\end{tabular}



Table 1. Coefficients of the time dependent degradation rate $\left(A t^{n}\right)$ of various parameters in a 0.3 Mm MOSFET stressed at $V_{G}=1.4 \mathrm{~V}$ and $V_{D}=4.4 \mathrm{~V}$.

Fig. 1. Degradation of various parameters in a $0.3 \mathrm{Mm}$ transistor. 
A computerized data acquisition system enabled us to study simultaneously several transistors and monitor the evolution of their parameters. Figure 1 shows the degradation of the main parameters (threshold voltage $V_{t}$, maximum of transconductance $G_{m}$, saturation current in reversed mode $\mathrm{I}_{\text {sat }}$, subthreshold slope) in a $0.3 \mathrm{\mu m}$ transistor. The time dependent degradation rate of all these parameters follows the classical law $\mathrm{At}^{\mathrm{n}}$ (see Table 1). The highest value of $\mathbf{n}$ corresponds to the subthreshold swing but no increase in the off-state leakage current is observed. In contrast, the threshold voltage shift is higher than in the micronic transistors, probably because of the greater ratio between the degraded region length and the effective channel length. The usual equivalence between a $10 \%$ degradation in transconductance and a $10 \mathrm{mV}$ shift in $\mathrm{V}_{t}$ does no longer hold in this case (Figs.1 and 2).
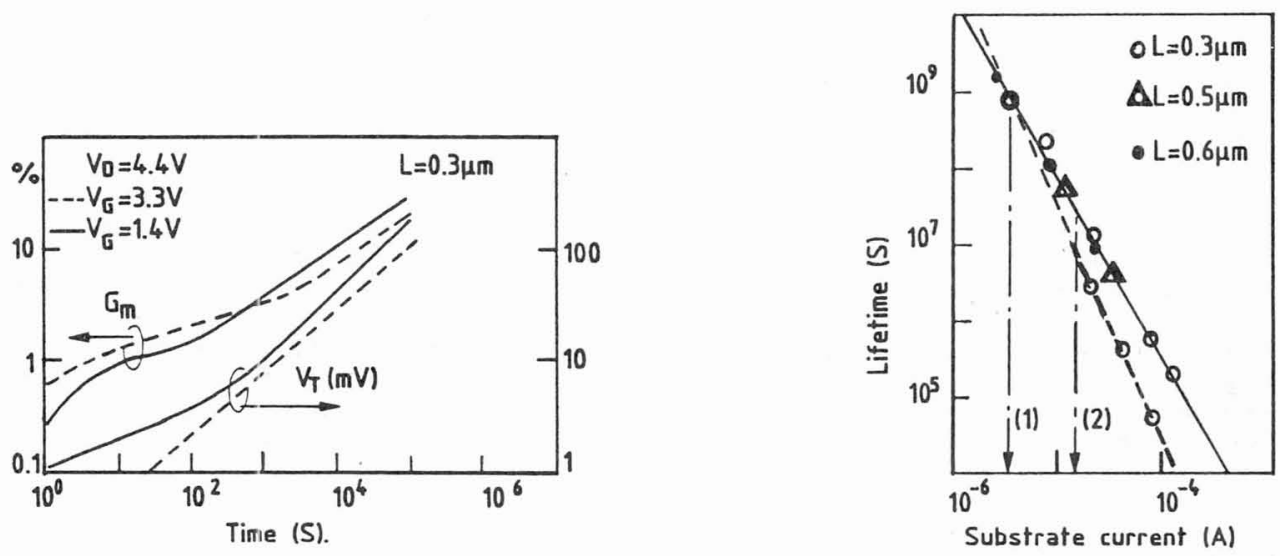

Fig. 2. Transconductance degradation and threshold voltage shift versus time for two stressing conditions.

Fig. 3. Device lifetime corresponding to a $10 \%$ variation in the saturation current (solid line) and to a $10 \mathrm{mV}$ shift in the threshold voltage (dashed line) versus substrate current. The duty ratio is $10 \%$. (1) and (2) correspond to the case of the shorter transistor (0.3Mm) biased at $V_{D}=3 V$ and $3.5 V$ respectively.

In order to extrapolate the device lifetime, we have chosen two different criteria : (1) $10 \%$ decrease in the reverse mode saturation current (for $V_{g}=V_{d}=3 \mathrm{~V}$ ) and (2) $10 \mathrm{mV}$ shift in $\mathrm{V}_{\mathrm{t}}$. The two corresponding lifetimes are plotted in Fig.3. The classical dependence $r=C\left(I_{s u b}\right)^{-m}$ is very well fitted by $m=2.5$ for the saturation current and $m=3$ for the threshold voltage. Assuming a duty ratio of $1 / 10$ for CMOS technology, a 10 years lifetime can be obtained, with both criteria, at 3 V bias supply even for the shortest transistor $(0.3 \mathrm{Mm})$. For higher supply voltage the degradation becomes intolerable, the threshold voltage shift being the most limiting factor. This suggests the use of LDD like structures which are believed to reduce the threshold voltage shift and keep a good noise margin for these low voltage transistors. After stress we also noticed an increase by a factor of two in the substrate current due to the local trapping of negative charges that causes the lateral field to increase.

\section{3 - DETAILED CHARACTERIZATION OF THE DEGRADED DEVICES}

In order to determine the defective channel length $\Delta \mathrm{L}$, the type of the created defects, their density $\Delta \mathrm{N}_{\mathrm{q}}$ and the carrier mobility, we use a parameter extraction method especially conceived for degraded submicron devices $/ 2$. In this model, the damaged device is presented by the series combination of two transistors with different channel lengths and threshold voltages.

Figure 4 shows an original plot of the degradation rate of the channel resistance versus $V_{g}$, which illustrates the interaction between the defective and non defective regions of the channel : for $V_{g}<V_{t 1}$ both regions are in weak inversion, while for $V_{g}>V_{t 2}$ they are in strong inversion. For intermediate gate voltages only the defect free region reaches strong inversion while the degraded one is still in weak inversion. In other words, $\mathrm{V}_{\mathrm{t}_{1}}$ is the threshold voltage of the virgin device whereas $\mathrm{V}_{\mathrm{tz}}$ is that of the degraded region. This curve is in very good agreement with previous theoretical calculations $/ 2 /$. Table 2 gives the values of the threshold voltages shifts $\Delta V_{t}=V_{t 2}-V_{t 1}$, mobilities degradation rates $\mu_{1}-M_{2} / M_{1}$, degraded region lengths $\Delta L$ and densities of created defects $\Delta N_{q}$. It is found that the defective channel length $\Delta \mathrm{L}$ becomes more important for the higher gate voltage whereas the density of created defects is weaker.

In order to validate these results, we performed direct measurements of interface states were performed with the dynamic transconductance $/ 3 /$ and charge pumping $/ 4 /$ methods. The interface states generated for various conditions of stress are plotted versus drain current (Fig. 5). Indeed for each channel length, a constant drain current, at fixed $V_{d}$, is nearly equivalent to a constant inversion charge and a constant surface potential. We clearly observe that the density of created interface states is larger after stress at lower gate voltage $\left(V_{g}=1.4 \mathrm{~V}\right)$. 


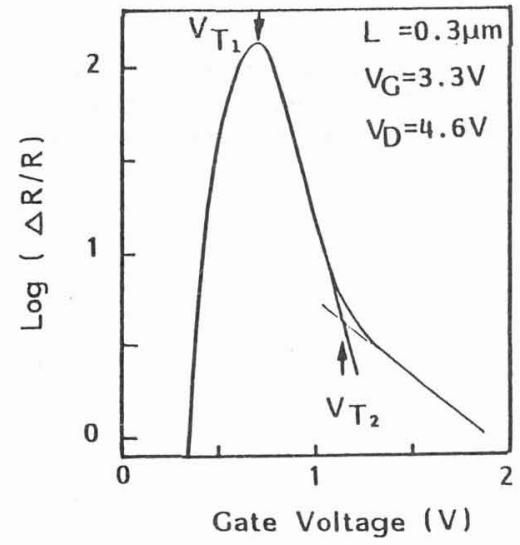

\begin{tabular}{|c|c|c|c|c|}
\hline Channel length & \multicolumn{2}{|c|}{$L=0.3 \mu \mathrm{m}$} & \multicolumn{2}{|c|}{$\mathrm{L}=0.6 \mu \mathrm{m}$} \\
\hline Bias conditions & $\begin{array}{l}V_{C}=3.3 \mathrm{~V} \\
V_{D}=4.6 \mathrm{~V}\end{array}$ & $\begin{array}{l}V_{C}=1.4 \mathrm{~V} \\
V_{D}=4.2 \mathrm{~V}\end{array}$ & $\begin{array}{l}V_{\mathrm{C}}=3.3 \mathrm{~V} \\
\mathrm{~V}_{\mathrm{D}}=4.6 \mathrm{~V}\end{array}$ & $\begin{array}{l}V_{C}=1.4 \mathrm{~V} \\
V_{D}=4.2 \mathrm{~V}\end{array}$ \\
\hline$\Delta L / L$ & $80 \%$ & $23 \frac{8}{8}$ & $10 \frac{9}{8}$ & $5 \%$ \\
\hline$\Delta \mu / \mu$ & $13 q$ & $20 \frac{9}{8}$ & $16 \frac{9}{8}$ & $23 \frac{8}{8}$ \\
\hline$\Delta V_{T}(V)$ & 0.37 & 0.45 & 0.28 & 0.42 \\
\hline$\Delta N_{q}\left(10^{11} \mathrm{eV}^{-1} \mathrm{am}^{-2}\right.$ & 5 & 6.5 & 4 & 6 \\
\hline
\end{tabular}

Fig. 4. Degradation rate of the channel resistance against gate voltage.

Table 2. Parameters of the degraded region of the channel, extracted for various cases. $V_{t 1}=0.78 \mathrm{~V}$.

\section{4 - DISCUSSION}

We notice from Table 2 that the ratio $\Delta \mathrm{L} / \mathrm{L}$ can be very large for the higher gate voltage. On the other hand, it is obvious from Table 2 and Fig. 5 that a higher density of interface states are produced at lower gate voltage, as in the case of long MOSFET's. A basic argument is provided by the simulation with MINIMOS of the electric field along the channel (Fig.6). We obseve firstly that the peak of the lateral electric field is almost constant with $V_{g}$, unlike the case of longer transistors where this peak is greatly reduced with increasing $V_{g}$; this is experimentally confirmed by the fact that the substrate current measued at fixed $V_{D}$ does not change significantly with $V_{G}$ from 1.4 to $3.3 \mathrm{~V}$. Secondly, the vertical field is enhanced by a factor of two when $V_{g}$ is increased from $1.4 \mathrm{~V}$ to $3.3 \mathrm{~V}$, making, therefore, easier the electron injection along a larger part of the channel.

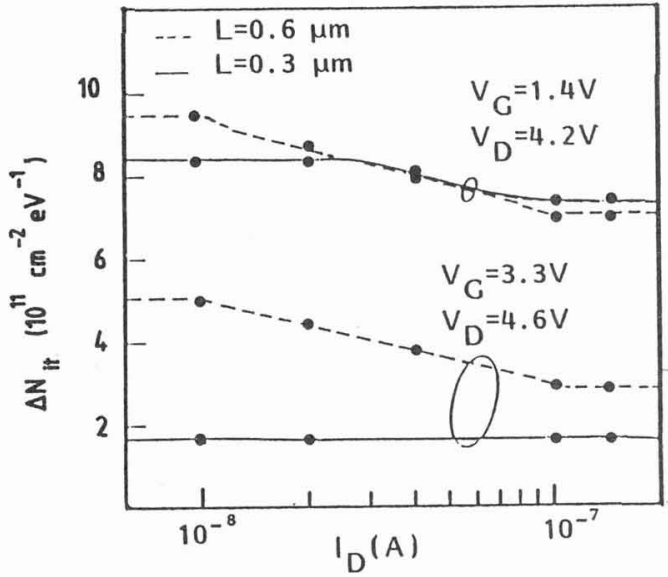

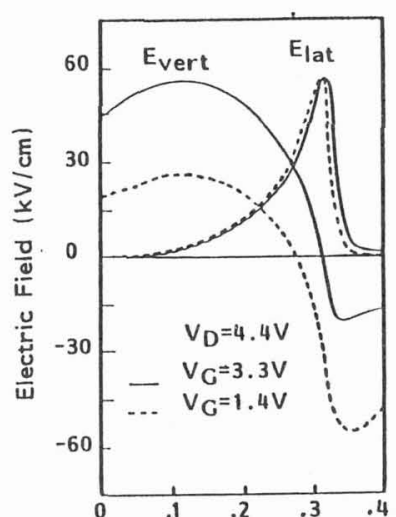

Position under the Gate $(\mu \mathrm{m})$

Fig. 5. Density of generated interface states versus drain cutrent after one week stress.

Fig. 6. Profiles of vertical and lateral fields along the channel.

For $\mathrm{V}_{\mathrm{g}}=1.4 \mathrm{~V}$, not only the electron injection should occur in a narrower region near the drain, but also the vertical field is there inverted, causing the simultaneous injection of hot holes and electrons. As the formation of interface states is usually explained by the injection of both holes and electrons, it is reasonable to measure a higher generation rate of interface states in this case.

To summarize, we think that for small values of the gate voltage a large amount of interface states are created in a very localised region near the drain. For higher gate voltages, the defective region greatly extends towards the source. This region contains trapped negative charges and, at a lower degree, interface states. This difference in the extension of the degraded region is confirmed by $I_{D}\left(V_{D}\right)$ curves measured in the saturation region : after stress at low $V_{G}$ the initial drain current value is recovered much earlier (i.e. for lower $V_{D}$ ) than after stress at higher $V_{G}$. 


\section{5- CONCLUSION}

The degradations of both the maximum transconductance and threshold voltage are greatly influenced by the extension of the defective channel length. The threshold voltage shift seems to be the most limiting factor for the lifetime of ultra short devices. Various degradation tests show that a 10 years lifetime can be achieved without LDD even for $0.3 \mu m$ transistors operated at $3 \mathrm{~V}$. However, an increase of the supply voltage would need the use of LDD structures.

\section{REFERENCES}

$1 /$ G. Guegan et al., ESSDERC 88.

$2 / \mathrm{H}$. Haddara and S. Cristoloveanu, SSE, in press.

/ / H. Haddara and S. Cristcloveanu, SSE, Vol.29, N8, 1986.

$/ 4 /$ H. Haddara and G. Ghibaudo, SSE, Vol.31, No6, 1988. 